\title{
The needs of informal caregivers and barriers of primary care workers toward dementia management in primary care: a qualitative study in Beijing
}

\author{
Meirong Wang ${ }^{1 \dagger}$, Shuang Shao ${ }^{1 \dagger}$, Jing $\mathrm{Li}^{2}$, Yingjie Liu', Xiaojingyuan $\mathrm{Xu}^{1}$ and Juan $\mathrm{Du}^{1^{*}}$ (D)
}

\begin{abstract}
Background: Informal caregivers of people with dementia in Beijing are increasingly called upon to provide homebased care for their patients due to the increasing number of dementia patients and the shortage of standardized institutional solutions of care for patients in China. This study aimed to clarify the needs of informal caregivers and barriers of primary care workers toward dementia management in primary care in Beijing to provide references that may help to improve the care and services provided to individuals with dementia and their family caregivers residing in urban China.

Methods: A mixed-methods approach was used in this study. We performed individual in-depth interviews with 10 informal caregivers. Moreover, we carried out focus group interviews with 29 primary care workers. Content analysis was used to separately identify themes and codes. Discrepancies were discussed until final agreement was achieved.

Results: Three themes representing the core attitudes of informal caregivers and primary care workers were identified: care knowledge and skills, psychological counseling, and collaborative management. Most primary care workers believed that the management of dementia patients in primary care was necessary. However, due to the heavy work load and different medical specialties involved, these workers were unable to manage it.

Conclusions: Professional training focused on dementia for primary care workers should be strengthened. At the same time, the establishment of a community-based dementia team management model that includes specialists, community health service centers (CHSCs), and community committees should be explored.
\end{abstract}

Keywords: Dementia, Primary care, Qualitative approach, Beijing

\section{Background}

Estimates show that the number of people with dementia will increase from approximately 46.8 million in 2015 to 131 million by 2050 worldwide. In 2016, the global societal economic cost of dementia was estimated to be US $\$ 818$ billion [1]. This situation challenges governments and health care providers to develop and improve services to people with dementia, with an emphasis on

\footnotetext{
* Correspondence: cuckoo@ccmu.edu.cn

${ }^{\dagger}$ Meirong Wang and Shuang Shao contributed equally to this work.

${ }^{1}$ School of General Practice and Continuing Education, Capital Medical

University, No.10 Xitoutiao, You An Men, Beijing 100069, China

Full list of author information is available at the end of the article
}

earlier diagnosis, the provision of support in the community, and the role of primary care services [2,3]. Case management is described as a collaborative process of assessment, planning, facilitation and advocacy for options to meet an individual's health needs through communication and available resources to promote quality, cost-effective outcomes [4]. Dementia case management interventions are becoming a major way to manage dementia patients in primary care in North America and Europe [5, 6]. A systematic review had demonstrated that some needs (e.g., education about the disease) of patients and caregivers were well targeted by dementia case management, while some very common needs (e.g.,

(c) The Author(s). 2018 Open Access This article is distributed under the terms of the Creative Commons Attribution 4.0 International License (http://creativecommons.org/licenses/by/4.0/), which permits unrestricted use, distribution, and reproduction in any medium, provided you give appropriate credit to the original author(s) and the source, provide a link to the Creative Commons license, and indicate if changes were made. The Creative Commons Public Domain Dedication waiver (http://creativecommons.org/publicdomain/zero/1.0/) applies to the data made available in this article, unless otherwise stated. 
early diagnosis) were still overlooked [7]. Furthermore, general practitioners (GPs) often lack knowledge about dementia, and confidence in recognizing the symptoms, they are unsure about how - or if - cognitive screening should be conducted, and often harbor beliefs that little can be done therapeutically in any case [8].

Compared with other countries worldwide, China is experiencing the greatest overall increase in its population of elderly residents. There were approximately 240 million people, or $17.3 \%$ of the population, who were aged 60 years or above in 2017 [9]. The number of people in China with dementia is also expected to increase from approximately 9.5 million in 2015 to 16 million by 2030 [1]. There is high-quality evidence suggesting that the total annual cost of dementia will increase from US\$900 million in 1990 to US\$114.2 billion in 2030 in China [10].

The current medical treatment and management of dementia in China is not promising. Only $10 \%$ of people with dementia have been diagnosed, while only $21 \%$ diagnosed dementia patients have received medical treatment in urban China [11]. Most people with dementia in China live at home, supported by informal caregivers [12]. The heavy care burden easily leads caregivers to have depression, anxiety and other negative emotions [13], which can cause them to vent their difficult emotions on their patients [14]. But there were also surveys $[15,16]$ shown that a strong sense of family responsibility might reduce the perception of care burden. Alternative care (respite service, institutional care, etc.) and professional support (professional knowledge and skills guidance, rehabilitation services for dementia patients, psychological support for caregivers, etc.) are important aspects of caregivers' care needs. However, these needs have not been met effectively [17].

The World Health Organization states that it would be challenging to intervene without the effective involvement of primary care, and dementia should be the priority of public health [18]. However, the national basic package of public health services which was promulgated by National Health and Family Planning Commission of China in 2017 only covered the management of hypertension, diabetes, psychosis and tuberculosis in community health services setting [19]. In 2015, the State Council of the People's Republic of China promulgated the National Five-year plan for Mental Health (2015-2020), which focused on four brain diseases (autism, schizophrenia, depression and dementia) occurring in different stages of life; the plan includes the development of integrated services, training of mental health specialists, improvement of rehabilitation services and community- and family-based support, as well as the promotion of social awareness [20]. Studies showed that community-care interventions (dietary adjustments, regular home visits, etc.) provided by primary care workers for dementia patients and their caregivers could improve the quality of life for patients and reduce the mental stress of caregivers and the burden of families [21-23]. However, qualified primary care workforces are not sufficient in China. Take GPs for example, there were only 1.82 licensed GPs per 10,000 people in 2017 [24]. Furthermore, a study in Shanghai showed that most GPs still lack training and related knowledge about dementia, and their attitudes toward the care of dementia are pessimistic [25].

As an aging city, there were approximately 150 thousand to 200 thousand dementia patients in Beijing in 2015 [26]. The population of people with dementia is still growing [27]. This qualitative study aimed to clarify the needs of informal caregivers and barriers of primary care workers toward dementia management in primary care in Beijing to provide references that may help to improve the care and services provided to individuals with dementia and their family caregivers residing in urban China.

\section{Methods}

A descriptive approach was chosen because the goal of the study was to elicit the needs of informal caregivers and barriers of primary care workers toward dementia management that would directly and pragmatically show their reality [28].

The topics for the caregivers and primary care workers were designed and modified based on the expert consensus on long-term healthcare of patients with cognitive disorders in China by academy of cognitive disorder of China - effective support by caregivers and physicians at lifestyle changes, cognitive maintenance and training [29]. At first the questions were roughly listed based on our literature review and status quo of primary care in China. Then they were categorized by the specific topics that represent the key components of the needs of informal caregivers and barriers of primary care workers' toward dementia management. We created the topics to ascertain a diversity of perceptions about the needs and barriers mentioned above to make consistent and reliable integration of perspectives from caregivers and primary care workers.

\section{Participants and recruitment}

The study was conducted in four CHSCs in Chaoyang district, Beijing. Twenty-five individuals who were diagnosed with dementia by neurologists in secondary or tertiary hospital were approached by the general practitioner of our research group via electronic health records.

Twenty-five main informal caregivers were approached by the inclusion criteria as follows: (1) minimum $2 \mathrm{~h}$ of daily care and the longest duration of care per day for patients at home over 6 months; (2) willingness to be 
interviewed as part of the study; and (3) could answer the interviewer's questions clearly and logically.

We purposively sampled primary care workers from the inner city and suburbs with a mix of primary care workers, sexes, ages and years of experience. Inclusion criteria were general practitioner or nurse qualifications, a current primary care practice and at least one patient with dementia.

\section{Data collection \\ Individual in-depth interviews}

In-depth interviews with caregivers were conducted from September to December 2017 by interviewers who received training and supervision in conducting qualitative interviews. The interviews were structured and included predetermined topics and associated probes. These predetermined topics were chosen by the research team to elicit, in an open-ended fashion, an exploration of caregivers' attitudes. The topics included who else provided support and assistance for you in the community during the care period, what else do you need while providing care, and who would you tend to ask for help if you run into trouble in the process of care. Field notes included difficulties encountered during the interviews and the interviewer's impressions of participants' reactions to the study. Participants were advised that the whole interview could be completed in $30 \mathrm{~min}$ but were not discouraged from extending the interview duration if willing. The interviews ranged from 30 to $90 \mathrm{~min}$ in length, which mostly lasted for approximately one hour.

\section{Focus groups}

To explore issues identified in the interviews, we conducted focus group with GPs and community nurses from January to February 2018. The objectives were to answer the following questions about primary care workers with respect to dementia: (a) the understanding of knowledge and skills of dementia care; (b) the attitudes, ability and difficulty in dementia management; (c) their advice on dementia care in the community.

After informing participants of the purpose of the study and obtaining written consent, four experienced moderators led the four groups simultaneously. An experienced researcher in qualitative study observed the groups' discussions and took notes. Each group was given the same task, namely, to identify the barriers to managing dementia in primary care and to suggest effective approaches that could overcome these barriers. Each session was approximately $90 \mathrm{~min}$ in length and was held in a private meeting room located in the health clinics.

\section{Data analysis}

All interviews and focus group discussions were audio recorded with consent from participants. Digital recordings were stored in a password-protected, secure system. Audio-taped data were transcribed verbatim. Transcripts were reviewed and analyzed by six members of the research team. To bring a wide variety of knowledge and preconceptions to the analysis process, the team comprised professionals with different research backgrounds, including an associate professor and a lecturer of general practice, three graduate students and a general practitioner. The team members read all the material through several times to obtain the whole sense and then independently coded transcripts to identify themes by condensing and summarizing the contents. When no new topics were identified, data saturation was considered [30].

We conducted a content analysis by analyzing the verbatim transcripts and identifying specific meanings and potential implications, in accordance with the topics. A second researcher conducted a second transcription after a researcher independently transcribed each audiotape. A third researcher then compared the first and second transcriptions for disparities. A final transcription was developed after the researchers collectively discussed the most accurate interpretation of the disparities. No new categories emerged in the analysis after the 8th interview, as interview no. 9 and 10 only added minimal information. Saturation of themes was reached after the fourth focus group and data-collection was stopped. We then reviewed the coded data for different approaches, which led to the combination of some codes, the identification of new subcodes and the production of a narrative summarizing the key themes of the discussions. A back-translation approach was also used, which involved translation to English and then double-checking for errors by a second independent researcher to ensure equivalence in both languages.

\section{Results \\ Sample}

According to the severity of the patient's condition, 12 informal caregivers of people with dementia were selected in Chaoyang district, Beijing. Only 10 caregivers were interviewed; 2 declined because they did not want to talk about their work. Most caregivers were either spouses $(6 / 10, n=6)$ or adult children $(3 / 10, n=3)$ (see Table 1 for additional characteristics). The primary care workers were recruited from 8 districts in Beijing, $75 \%$ of which were metropolitan. The 29 primary care workers (overall age range, 30-62 years; mean, $38.9 \pm 8.3$ years) represented a wide range of practice sizes and length of experience (range, 4-29 years; mean, $12.7 \pm 6.7$ years), and included 20 GPs and 9 community nurses. The ratio of male to female GPs in the groups was 3:17. Twenty GPs were divided into three groups of 7, 8 and 5 GPs; nine community nurses were in a group. 
Table 1 Characteristics of interviewed caregivers and care recipients

\begin{tabular}{|c|c|c|}
\hline Items & Caregivers $(n=10)$ & Care recipient $(n=10)$ \\
\hline Mean age & $66.9 \pm 16.6$ & $79.0 \pm 4.1$ \\
\hline \multicolumn{3}{|l|}{ Sex } \\
\hline Female & 9 & 2 \\
\hline Male & 1 & 8 \\
\hline \multicolumn{3}{|c|}{ Self-reported general health } \\
\hline Excellent/very good & 0 & N/A \\
\hline Good & 0 & N/A \\
\hline Fair & 3 & N/A \\
\hline Poor & 7 & $\mathrm{~N} / \mathrm{A}$ \\
\hline \multicolumn{3}{|l|}{ Relationship } \\
\hline Spouse & 6 & N/A \\
\hline Child & 3 & N/A \\
\hline Other family relative & 1 & N/A \\
\hline \multicolumn{3}{|l|}{ Marital status } \\
\hline Married & 9 & 8 \\
\hline Widowed & 1 & 2 \\
\hline \multicolumn{3}{|l|}{ Education } \\
\hline Elementary school & 0 & 2 \\
\hline Secondary school & 6 & 3 \\
\hline Higher education & 4 & 5 \\
\hline \multicolumn{3}{|l|}{ Severity of dementia } \\
\hline Mild & N/A & 5 \\
\hline Moderate & N/A & 3 \\
\hline Severe & $\mathrm{N} / \mathrm{A}$ & 2 \\
\hline
\end{tabular}

\section{Qualitative findings}

Analysis of the interviews with the caregivers and the focus groups with primary care workers led to the identification of three themes related to the needs of informal caregivers and barriers of primary care workers: care knowledge and skills, psychological counseling, and collaborative management.

Quotes are shown in italics. "C" stands for caregiver who participated in the interview, "GPA" stands for the first group of general practitioners, "GPB" stands for the second group of general practitioners, "GPC" stands for the third group of general practitioners, and "ND" stands for community nurse.

\section{Care knowledge and skills}

\section{Urgent needs for care knowledge}

To provide more appropriate care, almost all informal caregivers mentioned that they needed GPs or community nurses to provide professional care guidance. People caring for patients with mild dementia wanted to obtain care guidance about how to prolong the early process of the condition, how to address patients with abnormal behavior problems, how to enhance the patient's memory and how to improve the patient's ability to live. People caring for patients with severe dementia wanted to obtain skills to address dietary and toileting difficulties of their patients and wanted to know how to prevent the occurrence of complications or how to address them, etc. They also hoped that the primary care workers could offer home care services, such as injections.

My father-in-law's condition is not very severe, but we are not good at taking care of him. I hope to grasp some knowledge to prolong the process of the disease.(C8)

We need some professional care knowledge because we are not professional. (C7)

I learned stomach intubation care from nursing workers when my father was hospitalized. (C6)

I take care of my husband. He is bedridden now. I do not know whether it is good to take care of him like before. I am afraid to touch him. (C2)

He always gets inflamed. It's not easy for us to bring him to the CHSC because of his mobility problems. If the medical workers could do some follow-up regularly and offer injection services, it would be more convenient. (C6)

\section{Willing to help but lack professional training}

As for the primary care workers, they could provide only a small amount of help because of their heavy workloads and their lack of expertise related to dementia. The help provided to caregivers was mainly focused on the advice regarding usual care for the patients, such as dietary care, the prevention of accidents, and the prevention of complications for bedridden patients. Only three GPs said they had received training related to dementia, but they had already forgotten the specific details. Almost all the interviewees said they only had a preliminary understanding of the knowledge and skills of dementia. For them, the experience mostly came from clinical practice, books, and the web. All interviewees agreed that they lacked confidence regarding the management of dementia patients in primary care.

I like to help them. I educate the care providers by providing some care knowledge, such as pressure sores care, lung infection care. (N3)

I see almost 100 patients every day. It is difficult for me to guide the caregivers particularly. The specialists have a deeper understanding of dementia than us. I think they could provide more targeted advice. (GPB1) 
As a general practitioner, I pay more attention to the patients' physical diseases, such as high blood pressure and diabetes, not dementia. (GPC3)

The main thing we can do is to provide care for complications during dementia, such as lung infection and high blood pressure. (GPA1)

I did not accept any systematic training about dementia during residency. (GPB1)

I had managed patients with dementia during residency training of GPs, but my knowledge about dementia is not comprehensive. (GPA1)

\section{Psychological counseling Needs for psychological support}

The heavy care burden and pressure could easily lead caregivers to irritability, anxiety and other negative emotions. This might lead to a reduction in their ability to provide care and to the quality of the care services provided to the dementia patients. Caregivers need psychological consultations to ease the pressures they felt and to maintain their good emotional state.

I feel better now. I adjusted myself slowly... I felt helpless and anxious at the beginning. (C10)

Sometimes I get angry at my husband. He says he wants to separate from me. He always says something weird like that. (C4)

My mum fell in the bathroom a few days ago. Her head wedged in the crack of close stool and pillar. I called her, but she did not respond to me. If I discovered her later, she would never be saved. I am so scared. (C10)

His illness really bothers me. My condition was good before, but I feel uncomfortable with my heart recently. He depends on me for everything. I take care of him all day. I am really irritated. (C4)

He is stronger than me. He wanted to hit me that day. I was so grieved. (C3)

I would be extremely delighted to chat with someone. Nobody talks to me because they are busy. (C1)

\section{Limited help provided by primary care workers}

Primary care workers could give informal caregivers only limited psychological guidance and support because of the different medical specialties. Actually, there were already some patients with dementia and their caregivers who had established telephone contact, WeChat (a mobile text and voice messaging communication service) and other contacts with their GPs to accept personalized guidance about psychological problems.

I think it is still necessary for the specialists to see patients in CHSCs. Sometimes when we say something to the caregivers or patients to express our empathy, they refute us. They think that we cannot understand their feelings. Psychologists have specialized knowledge and they know how to deal with it. (GPB1)

Some caregivers are in my WeChat list. If there is any special situation, he can consult me directly on WeChat. I will give him a reply when I have time. I think this is a more personalized guide, but the help I provide is very basic and limited. (GPB2)

As a community health worker, we should increase the public awareness of dementia, help the patients and caregivers as much as possible in various ways. (GPC2)

\section{Collaborative management} Expectations of respite services

Lack of social contact was a common situation among caregivers. They rarely arranged leisure or social activities, especially those caring for patients who could not take care of themselves. To improve the quality of care, collaboration was necessary. Most informal caregivers were spouses; they were older, and their body functions degenerated gradually. They felt physically overextended and exhausted, and their health condition was becoming gradually worse in the process of taking care of their patients.

The main thing is that I do not have any time to socialize. I have no energy and I'm tired all the time. (C7).

I have to take care of my dad. I really do not have time to take care of my own family. I feel sorry for them. (C6)

He likes to go out for a walk, but my body is in a bad situation. I am unable to follow him, and I hope there is someone to follow him. (C1)

\section{Team-based management model}

Almost all the primary care workers in the interview indicated that a team-based management model should be established. GPs should be mainly responsible for the 
early identification and the monitoring of dementia, maintaining the overall physical condition of patients and the overall coordination of the team. Community nurses would undertake care guidance, including life guidance and regular follow-up. In addition, the team also needed to have specialists, such as neurologists or psychiatrists. They could offer professional guidance to the GPs and provide support to the caregivers by seeing patients in CHSCs regularly.

\section{I think it should be a team. Apart from GPs and community nurses, specialists should be involved according to the patients' situation and caregivers' needs. GPs are mainly responsible for the overall physical condition of patients and specialists solve the specific problems. In addition to providing care guidance, community nurses can also do some follow-up. (GPB4)}

As the most accessible social resource for patients, community committees should cooperate with the CHSCs to play an active role in organizing patient exchange activities and other events and in coordinating available social resources to help the patients and their caregivers, such as helping to contact care institutions.

Community nurses provide some care guidance of patients' daily life for caregivers, such as prevention of accidental injury. GPs and specialists maintain the patients are in a stable physical condition and provide some psychological support for caregivers. I think this is the best way. It is also good for community committees and care institutions to provide some help because taking care of such patients is not unilateral. More participants, better quality of care work. (N1)

\section{Discussion}

In this study, two caregivers of people with dementia declined. The possible reasons tended to be either lack of knowledge on the part of the families/patients or the stigma sometimes attached to dementia. There is an overall low level of understanding of the condition of dementia among the public and the nonspecialist domain, which, alongside the stigma that might be attached, makes it difficult for people to discuss. One strategy to enhance attendance and eliminate stigma is by educating society [31]. The public health system in China has been working hard on promoting the social awareness through mental health propaganda and education in hospitals, communities and schools to reduce or eliminate stigma [12]. Since 2012, the appellation of "lao nian xing chi dai" with derogatory meaning in Mandarin has been gradually replaced by "cognitive disorder" in Chinese health care system [32].
People with dementia need help with challenging changes in behavior, memory, physical disability, and mood [33]. Informal caregivers need to know the characteristics of dementia and have knowledge of disease-related therapies and care. The needs for related knowledge persist from the early stages of the patients' disease; as the disease progresses, the focus of caregivers' needs change as well. An intervention that examined care skills was carried out in the caregivers of elderly patients with dementia; the research looked at skills that included coping styles, cognitive rehabilitation training and daily life care principles. The results showed that anxiety and depression of the caregivers were relieved and that the life quality score improved after the intervention [34]. Technology such as faceto-face interactions via various secure video connection platforms, and devices that monitor the health status or function of an older adult can be helpful for individuals who are caring for someone at home, especially to those who have heavily care duties and have difficulty leaving the home. In addition, the guidance and application of predictive care can also help to minimize further harm, risk and cost for the patient and the psychological burden on caregivers [35]. In China, GPs are often inadequately trained and may be reluctant or unable to detect, diagnose or manage dementia [36]. The results of the interviews also showed GPs were more focused on the physical diseases of their dementia patients and paid insufficient attention to their dementia, similar to a previous survey conducted in Shanghai, China [25]. Guidelines for the management of dementia in primary care have been established in Australia and Canada [37, 38]. These guidelines are intended to be used by health professionals and policy makers who plan, organize and deliver care for people who have dementia and their caregivers. Therefore, the domestic management of dementia in primary care should focus on strengthening the professional training regarding dementia for medical workers and establishing guidelines that suit the national culture.

Psychological counseling for caregivers is an important part of care. The caregivers' positive mental attitudes are the basis for the implementation of care. In America, GPs periodically assess caregivers for the level of perceived burden, presence of depression and anxiety, and coping strategies, and they help the patient and caregiver with care planning in advance. Community nurses, social workers, rehabilitation specialists, and psychologists provide support services such as health education, psychological counseling, and emotional support for caregivers [39]. Therefore, given the needs of caregivers in China, it is recommended that this model be used as a reference. Meanwhile, hospitals and CHSCs provide psychological counseling and care 
guidance for the caregivers collectively and organize gatherings for caregivers on a regular basis to promote the sharing of feelings and care skills. In addition, respite service is necessary according to the caregiver's work and physical condition to deliver an individualized, simple, flexible, and adaptable response to caregivers' needs [40].

Community management of dementia involves a wide range of areas, requiring multidisciplinary collaboration. Various social resources in addition to primary care support should also be noted. Community committees, neurologists and psychologists in secondary and tertiary hospitals should be available to collaborate. A clear and robust multidisciplinary expert group will enable diagnosis and management [41] and enhance patient and caregiver satisfaction [42]. This integration of medical and social services, emphasizing multidisciplinary and multidomain team communication and collaboration of the personalized management model, fully embodies the principle of being "patient centered".

In North America and Europe, case management has become an important way for primary care providers to manage dementia in communities. Case managers are mostly nurses who care for the dementia patients; they work with GPs, assisting physicians in conducting examinations around the diagnosis, coordinating treatment plans, providing health education on diseases, suggesting available resources and reporting the health status and needs of patients and caregivers regularly. The GPs are responsible for providing medical treatment, developing a care plan, and adjusting the plan according to the feedback of the case managers [7]. Domestic case management was first introduced in Taiwan and Hong Kong and has a short development history in the mainland. The current application in community schizophrenia is relatively mature and has achieved a significant effect [43]. Prior work showed that patients' cognitive ability, self-care ability and quality of life were all improved through the application of dementia case management [44]. Case management not only had a positive impact on dementia patients and caregivers themselves but also improved the utilization of community health resources and reduced the cost of health care [45]. To some extent, services provided will be dependent on local provisions, demography, and geography, but even if the services are available, if the understanding or relationship of expectations between the GPs and specialists is dysfunctional, then patients will not receive the high quality of care that they deserve [46]. At present, the case management of dementia in China is still at an exploratory stage. There is no clear definition of team formation rules, implementation processes of case management and evaluation of management effectiveness. Based on these concerns, the establishment of a community-based dementia team management model that suits the national culture should be explored.
It became clear that there were many similar aspects about the needs of informal caregivers and barriers of primary care workers toward dementia management in primary care between China and some Western countries. More-general expectations were described by informal caregivers (e.g., sharing the responsibility of caring for dementia patients and making joint decisions regarding the care) [47] and primary care workers (e.g., time constraints and lack knowledge about dementia) [48]. Different aspects were also existed. General practitioners in Western countries perceived lack of knowledge of early diagnostic, and some of them seemed to attach stigma to the condition of dementia by assuming that the caregiver/patient did not want a diagnosis until the symptoms were so severe that it was inevitable [48]. However, these contents were not reflected in our study. We think there are two potential reasons. First, the GPs working in CHSCs are generally less educated in China. Only 44.8\% GPs had a bachelor degree or above compared with $69.9 \%$ physicians in the secondary and tertiary hospitals [49]. The perceived low quality of primary care is a major reason why people prefer to use hospital care. Second, the management of specific chronic diseases required by the government is an important job for CHSCs. Therefore, primary care workers rarely show more initiative on diseases not required by the government.

After the researchers collectively discussed the most accurate interpretation of the disparities, a final transcription was developed to make consistent and reliable integration of perspectives from caregivers and primary care workers, which increases the confidence in our findings. But this study has its limitations. It is an exploratory study, only the informal caregivers in Chaoyang district were recruited. The representativeness of informal caregivers in this study was relatively limited. We plan to do further studies in other districts of Beijing.

\section{Abbreviations \\ C: Caregiver who participated in the interview; CHSCs: Community Health Service Centers; GPA: The first group of general practitioners; GPB: The second group of general practitioners; GPC: The third group of general practitioners; GPs: General practitioners; N: Community nurse}

\section{Acknowledgments}

The authors thank Guanghui Jin for his editorial help. To all the caregivers and primary care workers who participated in this research, the authors convey their sincere thanks and respect for their contribution and sharing of experiences.

\section{Funding}

This work was supported by the Capital General Practice Research Project (17QK05). The funding organization had no role in the design, conduct, analysis and interpretation or preparation of the report of this study.

\section{Availability of data and materials}

The datasets generated and analyzed during the current study are not publicly available to protect participant privacy, but are available from the corresponding author on reasonable request. 


\section{Authors' contributions}

MRW, SS, JL, YJL, XJYX and JD contributed to the conception and design of this study. MRW SS, JL, YJL and XJYX were involved in data collection. MRW $S S, J L, Y J L, X J Y X$ and JD analyzed and interpreted the data. The manuscript was drafted by MRW and SS and edited by JD. The final version was reviewed and approved by all authors.

\section{Ethics approval and consent to participate}

This study was approved by the Medical Ethics Committee of Capital Medical University, Beijing, China. Written informed consent was obtained from each participant involved in this study. All participant information was kept confidential.

\section{Consent for publication}

Not applicable.

\section{Competing interests}

The authors declare that they have no competing interests.

\section{Publisher's Note}

Springer Nature remains neutral with regard to jurisdictional claims in published maps and institutional affiliations.

\section{Author details}

${ }^{1}$ School of General Practice and Continuing Education, Capital Medical University, No.10 Xitoutiao, You An Men, Beijing 100069, China. ${ }^{2}$ Dongfeng Community Health Service Center, Chaoyang District, Beijing, China.

Received: 23 August 2018 Accepted: 11 December 2018 Published online: 20 December 2018

\section{References}

1. Prince M, Comas-Herrera A, Knapp M, Guerchet M, Karagiannidou M. World Alzheimer report 2016. In: The global voice on dementia. Alzheimer's disease international. 2016. https://www.alz.co.uk/research/ WorldAlzheimerReport2016. Accessed 22 Aug 2018.

2. Global Alzheimer's Disease Charter. In: The global voice on dementia. Alzheimer's disease international. 2008. https://www.alz.co.uk/global-charter. Accessed 22 Aug 2018

3. Alzheimer Europe. Policy in practice: Paris declaration. 2015. http://www alzheimer-europe.org/EN/Policy-in-Practice2/Paris-Declaration. Accessed 22 Aug 2018.

4. Case Management Society of America. What is a case manager? 2016 http://www.cmsa.org/who-we-are/what-is-a-case-manager/. Accessed 22 Aug 2018.

5. Bamford C, Poole M, Brittain K, Chew-Grahamet C, Fox C, lliffe S, et al. Understanding the challenges to implementing case management for people with dementia in primary care in England: a qualitative study using normalization process theory. BMC Health Serv Res. 2014;14(1):549.

6. Niffe S, Robinson L, Bamford C, Waugh A, Fox C, Livingston G, et al. Introducing case management for people with dementia in primary care: a mixed-methods study. Br J Gen Pract. 2014;64(628):735-41.

7. Khanassov $V$, Vedel I. Family physician-case manager collaboration and needs of patients with dementia and their caregivers: a systematic mixed studies review. Ann Fam Med. 2016;14(2):166-77.

8. Spenceley SM, Sedgwick N, Keenan J. Dementia care in the context of primary care reform: an integrative review. Aging Ment Health. 2015;19(2): 107-20.

9. National Bureau of Statistics of the People's Republic of China. Beijing: The National Bureau of Statistics. The national economic and social development statistical bulletin 2017. 2017. [in Chinese], http://www.stats. gov.cn/tjsj/zxfb/201802/t20180228_1585631.html. Accessed 22 Aug 2018.

10. Xu J, Wang J, Wimo A, Fratiglioni L, Qiu C. The economic burden of dementia in China, 1990-2030: implications for health policy. Bull World Health Organ. 2017:95(1):18-26.

11. Yu X, Chen S, Chen X, Jia J, Li C, Liu C, et al. Clinical management and associated costs for moderate and severe Alzheimer's disease in urban China: a Delphi panel study. Transl Neurodegener. 2015;4(1):15.

12. Chen $Z$, Yang $X$, Song YT, Song BB, Zhang Y, Liu JW, et al. Challenges of dementia care in China. Geriatrics. 2017;2(1):7.
13. Arango Lasprilla JC, Moreno A, Rogers $H$, Francis $K$. The effect of dementia patient's physical, cognitive, and emotional/behavioral problems on caregiver well-being: findings from a Spanish-speaking sample from Colombia, South America. Am J Alzheimers Dis Other Demen. 2009;24(5):384.

14. Yang PP, Shen J. Abuse tendency among dementia caregivers: a qualitative research. Chin J Prac Nurs. 2013:29(1):27-30 (in Chinese).

15. Tang $Y$. The establishment of mental health and long-term care system for the main caregivers of the disabled elderly. Academic Forum. 2012;35(9): 168-73 (in Chinese)

16. Abdollahpour I, Nedjat S, Salimi Y. Positive aspects of caregiving and caregiver burden: a study of caregivers of patients with dementia. J Geriatr Psychiatry Neurol. 2017;31(1):34-8.

17. Hao W, Wu J, Zhang H, Zou BH, Wang ZW. Supportive care demands of family caregivers of community-dwelling patients with dementia. Chin Nurs Manag. 2015:15(11):1294-7 (in Chinese).

18. World Health Organization. Dementia: a public health priority. 2012. http:// apps.who.int/iris/bitstream/handle/10665/75262/WHO_NMH_MSD_2012.3 eng.pdf? sequence=1\&isAllowed=y. Accessed 22 Aug 2018.

19. National Health Commission of the People's Republic of China. Nationa Basic Public Health Service Regulations (the Third Edition). 2017. [in Chinese], http://www.nhfpc.gov.cn/ewebeditor/uploadfile/2017/04/ 20170417104506514.pdf. Accessed 28 Oct 2018.

20. The State Council of the People's Republic of China. The National Five-year plan for mental health (2015-2020). 2015. [in Chinese], http://www.gov.cn/ zhengce/content/2015-06/18/content 9860.htm. Accessed 22 Aug 2018.

21. Lu FH, Zeng H, Ji SY, Zhu HR, Lv XF. A review of community nursing interventions for Alzheimer's disease. J Nurs Sci. 2016;31(13):110-3 (in Chinese)

22. Xiao WY, Zheng $\mathrm{SH}, \mathrm{He} X \mathrm{Z}$. The effect of community nursing intervention on quality of life of Alzheimer patients and caregivers. Chin J Gen Pract. 2016:14(1):150-2 (in Chinese).

23. Zhang $W L$, Zhao $L$. Effect of community nursing intervention on dementia patients and their caregivers. J Clin Med. 2014;1(12):2254 (in Chinese).

24. Planning Development and Information Technology Division. The national development of health care statistical bulletin in 2017. 2017. [in Chinese], http://www.nhfpc.gov.cn/guihuaxxs/s10743/201806/ 44e3cdfe11fa4c7f928c879d435b6a18.shtml. Accessed 28 Oct 2018

25. Yu L, Xu Q, Wang ZY, Chen G, Cao WY, Mi JH, et al. A survey on the attitudes and confidence of GPs in handling dementia and its related problems. Natl Med J China. 2013;93(35):2794-8 (in Chinese).

26. National Health Commission of the People's Republic of China. Beijing: 150 thousand to 200 thousand dementia patients, many hospitals have a memory loss clinic. 2015. [in Chinese], http://health.china.com.cn/2015-04/ 17/content_7835452.htm. Accessed 22 Aug 2018.

27. Central People's Government of the People's Republic of China. There are 3. 29 million elderly people registered in Beijing, and the aging population has exceeded 24\%. 2017. [in Chinese], http://www.gov.cn/xinwen/2017-10/ 31/content 5235685.htm. Accessed 22 Aug 2018.

28. Jiggins CK, Evans B. Qualitative descriptive methods in health science research. Herd. 2016:9(4):16-25.

29. Academy of Cognitive Disorder of China. Expert consensus on long-term healthcare of patients with cognitive disorders in China. Chin J Geriatr. 2016;35(10):1051-60 (in Chinese)

30. Caelli K, Ray L, Mill J. 'Clear as mud': toward greater clarity in generic qualitative research. Int J Qual Method. 2003;2(2). https://doi.org/10.1177/ 160940690300200201

31. Department of Health. Living well with dementia: a national dementia strategy. 2009.https://www.gov.uk/government/publications/living-wellwith-dementia-a-national-dementia-strategy. Accessed 22 Aug 2018

32. China Central Television. Caring for the elderly, dementia changed its name to cognitive disorder. 2012. [in Chinese], http://tv.cntv.cn/video/C10616/ d3fa304b2ae94e399c6061ec19812d00. Accessed 1 Nov 2018.

33. Hg VDR, Meiland FJ, Maroccini R, Comijs HC, Jonker C, Dröes RM. Subjective needs of people with dementia: a review of the literature. Int Psychogeriatr. 2007:19(3):559-92

34. Dong CF. Nursing intervention for the main caregivers of dementia patients Chin J Trauma and Disability Med. 2012;20(5):107-9 (in Chinese).

35. Hu P, Liu Q. Effects of predictive nursing on elderly patients with Alzheimer's disease. Nurs J Chin PLA. 2013:30(10):32-4 (in Chinese).

36. Patel V, Xiao S, Chen H, Hanna F, Jotheeswaran AT, Dan L, et al. The magnitude of and health system responses to the mental health treatment gap in adults in India and China. Lancet. 2016;388(10063):3074-84. 
37. Palk E, Carlson L, Parker D, Abbey JA. Clinical practice guidelines and care pathways for people with dementia living in the community. In: Cognition/ dementia care system. 2008. https://www.researchgate.net/publication/ 27476359. Accessed 22 Aug 2018.

38. Diagnosis and Management in Primary Care. Cognitive ImpairmentRecognition. British Columbia. 2016. https:/www2.gov.bc.ca/gov/content/ health/practitioner-professional-resources/bc-guidelines/cognitive-impairment. Diagnosis and Management in Primary Care. Accessed 22 Aug 2018.

39. Dang S, Badiye A, Kelkar G. The dementia caregiver--a primary care approach. South Med J. 2008;101(12):1246-51

40. Yang XL, Chen M, Zhang H, Tian AJ, Li L. Application of Plato analysis in negative influencing evaluation of Alzheimer caregivers. J Nurs Train. 2014; 22:2046-7 (in Chinese).

41. De L, Wind AW, Iliffe S, Moniz-Cook ED, Wilcock J, González VM. The primary care diagnosis of dementia in Europe: an analysis using multidisciplinary, multinational expert groups. Aging Ment Health. 2008; 12(5):568-76.

42. Hinton L, Franz CE, Reddy G, Flores Y, Kravitz RL, Barker JC. Practice constraints, behavioral problems, and dementia care: primary care physicians' perspectives. J Gen Int Med. 2007;22(11):1487-92.

43. Liu JH, Hao, Chen H, Xiang YQ, Qiu D, Li YJ Community social function of schizophrenia application case management interventions to improve performance evaluation J Int Psychia 2016; (1):72-6. (in Chinese).

44. Li W, Zhang XY, Zhao ZR. Study on the effect of case management on improving the quality of life of patients with dementia. Chin J Clin Rat Drug Use. 2014:27:163-4 (in Chinese).

45. Pimouguet C, Lavaud T, Dartigues JF, Helmer C. Dementia case management effectiveness on health care costs and resource utilization: a systematic review of randomized controlled trials. J Nutr Health Aging. 2010;14(8):669-76.

46. Iliffe S, De LJ, Van HH, Kenny G, Lewis A, Vernooijdassen M. Understanding obstacles to the recognition of and response to dementia in different European countries: a modified focus group approach using multinational, multi-disciplinary expert groups. Aging Ment Health. 2005;9(1):1-6.

47. Stephan A, Bieber A, Hopper L, Joyce R, Irving K, Zanetti O, et al. Barriers and facilitators to the access to and use of formal dementia care: findings of a focus group study with people with dementia, informal carers and health and social care professionals in eight European countries. BMC Geriatr. 2018;18(1):131.

48. Iliffe S. Rapid appraisal of barriers to the diagnosis and management of patients with dementia in primary care: a systematic review. BMC Fam Pract. 2010;11:52.

49. China Ministry of Health. Yearbook of Chinese health statistics 2018. 1st ed. Beijing: Peking Union Medical College; 2018.

Ready to submit your research? Choose BMC and benefit from:

- fast, convenient online submission

- thorough peer review by experienced researchers in your field

- rapid publication on acceptance

- support for research data, including large and complex data types

- gold Open Access which fosters wider collaboration and increased citations

- maximum visibility for your research: over $100 \mathrm{M}$ website views per year

At $\mathrm{BMC}$, research is always in progress.

Learn more biomedcentral.com/submissions 